\title{
Study of the Effectiveness of Brain Exercise Training and Intensive Short-Term Dynamic Psychotherapy (ISDTP) on Emotional Self-Awareness of Mothers with Mentally Retarded Children in Ahvaz
}

\author{
Estudio de la efectividad del entrenamiento con ejercicios \\ cerebrales y la psicoterapia dinámica intensiva a corto plazo \\ (ISDTP) sobre la autoconciencia emocional de las madres con \\ niños con retraso mental en Ahvaz
}

\author{
Maryam Ghanavati \\ Department of Psychology, Ahvaz Branch, Islamic Azad University, Ahvaz, Iran \\ ORCID: https://orcid.org/0000-0003-3208-6761 \\ Sahar Safarzadeh \\ Department of Psychology, Ahvaz Branch, Islamic Azad University, Ahvaz, Iran \\ ORCID: https://orcid.org/0000-0002-6571-1829
}

Received 02-12-20 Revised 03-13-20 Accepted 07-13-20 On line 08-29-20

*Correspondence

Email: Safarzadeh1152@gmail.com
Cite as:

Ghanavati, M., \& Safarzadeh, S. (2020). Study of the Effectiveness of Brain Exercise Training and Intensive Short-Term Dynamic Psychotherapy (ISDTP) on Emotional Self-Awareness of Mothers with Mentally Retarded Children in Ahvaz. Propósitos y Representaciones, 8 (SPE2), e693. Doi: http://dx.doi.org/10.20511/pyr2020.v8nSPE2.693 


\section{Summary}

Nowadays, study of the conditions of families with mentally retarded children, especially their mothers, is of great interest to researchers. Therefore, the present study aimed to investigate the Effectiveness of Brain Exercise Training and Intensive Short-Term Dynamic Psychotherapy (ISDTP) on Emotional Self-Awareness of Mothers with Children with Mentally Retarded Children in Ahvaz in the spring 2020. The statistical population of the study included all mothers of mentally retarded children in Ahvaz who were selected by available sampling method of 45 mothers and were divided into three groups of 15 (two experimental groups and one control group) by lot. The research design was experimental with pre-test and post-test with control group. The instruments used were Grant et al. (2002) Emotional Self-Awareness Questionnaire, which were completed in two stages before the intervention and at the end of the intervention. The results of the study using multivariate analysis of covariance and Bephroni post hoc test showed that the groups of brain exercise training and short-term dynamic psychotherapy in comparison with the control group are effective in increasing the emotional self-awareness of mothers of mentally retarded children. The results also showed that both methods are effective in increasing emotional self-awareness.

Keywords: Effectiveness Of Education; Brain Exercise; Short-Term Dynamic Psychotherapy; Emotional Self-Awareness; Mentally Retarded Children.

\section{Resumen}

Hoy en día, el estudio de las condiciones de las familias con niños con retraso mental, especialmente sus madres, es de gran interés para los investigadores. Por lo tanto, el presente estudio tuvo como objetivo investigar la efectividad del entrenamiento con ejercicios cerebrales y la psicoterapia dinámica intensiva a corto plazo (ISDTP) sobre la autoconciencia emocional de las madres con niños con retraso mental en Ahvaz en la primavera de 2020. La población estadística del estudio incluyó a todas las madres de niños con retraso mental en Ahvaz que fueron seleccionadas por el método de muestreo disponible de 45 madres y se dividieron en tres grupos de 15 (dos grupos experimentales y un grupo de control) por lote. El diseño de la investigación fue experimental con prueba previa y prueba posterior con grupo de control. Los instrumentos utilizados fueron Grant et al. (2002) Cuestionario de autoconciencia emocional, que se completó en dos etapas antes de la intervención y al final de la intervención. Los resultados del estudio que utiliza el análisis multivariado de covarianza y la prueba post hoc de Bephroni mostraron que los grupos de entrenamiento con ejercicios cerebrales y psicoterapia dinámica a corto plazo en comparación con el grupo control son efectivos para aumentar la autoconciencia emocional de las madres de niños con retraso mental .Los resultados también mostraron que ambos métodos son efectivos para aumentar la autoconciencia emocional.

Palabras clave: Componente sociopsicológico; Imagen; Análisis de correlación; Institución educativa superior.

\section{Introduction}

Emotional self-awareness is one of the factors that can affect the mental health and quality of life of mothers with mentally retarded children. Mental retardation or so-called mental retardation is 
not a new issue. Rather, in every period and time, there were people in the society who were not normal in terms of mental activities and needed special help from the family or their maintenance in special schools and centers (Hagh Ranjbar and et al., 2011).

Among the approaches that help mothers with mentally retarded children are brain exercise and short-term dynamic psychotherapy. Exercise therapy also helps mothers with mentally retarded children to improve these characteristics. Studies of how the brain works and its effect on learning have highlighted the importance and role of working memory, attention and executive function of the brain. Brain exercise is a set of sports movements that stimulate the brain, promote nerve conduction and facilitate learning in the brain. This program is based on the belief that learning problems are caused by a mismatch between the brain and body and thus reduce a person's ability to learn (Abduh and Tahar, 2018).

Doing these exercises helps the brain to be more focused. For example, the connection method increases positive mood, self-control and increases the range of attention (Ardian and Nourain, 2018). Brain exercise is known as motor skills training and was formally studied by Denison and Denison in 1970. Brain exercise includes a set of movements that stimulate the apparent activity of the brain, stimulate the nerves and facilitate learning in the brain. The program is based on the notion that learning disabilities are caused by a mismatch between the brain and the body and thus block a person's ability to learn (Denison and Denison, 1994).

Brain exercise is very effective on exercise, music and dance and it harmonizes both hemispheres of the brain (Hanaford, 2005). In this way, changes in learning and behavior are often immediate and profound and students learn how to simultaneously receive and express information (Denison, 1986).

Another factor that can affect the mental health of mothers with mentally retarded children is short-term dynamic psychotherapy. Short-term dynamic psychotherapy was developed through the activities of Malan, Siphnius, Dovanlo, Pollack, Horner, and De Jang (Driessen, Cuijpers, Matt, Abbass, Jonghe \& Dekker, 2009).

The aim of this study was to investigate the effectiveness of brain exercise training and short-term dynamic psychotherapy (ISDTP) on emotional self-awareness in mothers of mentally retarded children in Ahvaz.

Partial purpose (specific)

Determining the difference between brain exercise training and short-term dynamic psychotherapy (ISDTP) on emotional self-awareness of mothers with mentally retarded children in Ahvaz.

Research question

Does short-term dynamic psychotherapy (ISDTP) and brain exercise training affect the emotional self-awareness of mothers with mentally retarded children in Ahvaz? 


\section{Research Hypotheses}

Hypothesis 1: There is a difference between the groups of brain exercise training and short-term dynamic psychotherapy (ISDTP) and control in terms of emotional self-awareness in mothers with mentally retarded children.

Hypothesis 2: There is a difference between the groups of brain exercise training and control in terms of emotional self-awareness in mothers with mentally retarded children.

Hypothesis 3: There is a difference between the groups of short-term dynamic psychotherapy (ISDTP) and control in terms of emotional self-awareness in mothers with mentally retarded children.

Hypothesis 4: There is a difference between the groups of brain exercise training and short-term dynamic psychotherapy (ISDTP) in terms of emotional self-awareness in mothers with mentally retarded children.

\section{Conceptual and operational definitions of research variables}

Conceptual definition of emotional self-awareness: bodily sensation, desire for action, individual emotions, dependent emotions and a combination of mixed emotional experiences. Lack of awareness of experienced emotions makes it difficult for individuals to choose appropriate response strategies to overcome social situations (Kimi et al., 2012).

Operational definition of emotional self-awareness: In this study, emotional self-awareness refers to the score that subjects receive from the Grant et al. (2002) Emotional Self-Awareness Questionnaire.

Conceptual definition of brain exercise: Brain exercise involves a set of movements that stimulate the apparent activity of the brain, promote nerve conduction and facilitate learning in the brain. The program is based on the notion that learning disabilities are caused by a mismatch between the brain and the body and thus block a person's ability to learn (Denison and Denison, 1994). Brain exercise coordinates both hemispheres of the brain (Hanford, 2005).

Operational definition of brain exercise: In this study, 12 sessions of 60-minute brain exercise training according to Denison and Denison (1994) treatment protocol were obtained.

Conceptual definition of short-term psychodynamics: The emphasis of short-term dynamic psychotherapy is on immediate assistance to the patient to experience unconscious emotions that cause unconscious anxiety, disorder symptoms and various defenses (Perry and Bond, 2000).

Operational definition of short-term psychodynamics: In this study, 12 sessions of 60minute short-term dynamic psychotherapy were obtained according to Perry and Band treatment protocol (2000; quoted by Mohammadzadeh and Hosseini, 2018).

\section{Research background}

Fooladi, Borujeni, Ranjbar Sudjani (2018) in a study entitled (The effectiveness of intensive dynamic psychotherapy on social anxiety (ISDTP) short-term mothers with children with Asperger syndrome) showed that after controlling pre-test scores, a significant difference variable between post-test scores in the experimental group and follow-up scores on the social anxiety. 
Gholizadeh et al. (2016) in a study investigated the effect of aerobic exercise, anaerobic and relaxation on reducing stress and anxiety of female medical students of Kerman University of Medical Sciences. The results showed that there was a significant difference between the groups of aerobic exercise, anaerobic exercise and relaxation in reducing stress $(\mathrm{P} \leq 0.01)$ and anxiety $(\mathrm{P} \leq 0.05)$. Anxiety and stress were reduced in aerobic exercise and relaxation groups.

Rezaei, Ghazanfari and Rezaeian (2017) in a study entitled (Effectiveness of group parenting training on stress and parenting self-efficacy and behavioral problems of students with mental retardation) showed that positive parenting training on behavioral problems (severity of problem and frequency of problems) Students, parenting stress and parenting self-efficacy affect the mothers with intellectual disabilities students.

Hajloo and Mowlaie (2019) in a study comparing the effectiveness of short-term dynamic psychotherapy with an empathetic and anxiety-modifying approach to reducing the symptoms and maladaptive defense mechanisms of students with symptoms of adult separation anxiety disorder showed that empathetic and moderate therapy Incompatible defense mechanisms have had significant effects and the continuation of these changes in the two-month follow-up has been confirmed.

Bayanfar and Mousa Tabatabae (2019) in a study entitled The effectiveness of brain exercise training on the symptoms of attention deficit and concentration, academic self-efficacy and academic performance in students showed that brain exercise training can be a complementary therapeutic approach along with other therapeutic approaches, to be used to improve concentration and attention and increase the rate of learning and academic self-efficacy.

Nabizadeh, Farhadi, Rashid and Kordooghabi (2019) study the structure of the conflict triangle (emotion, anxiety, defense) with emphasis on interpersonal defenses and as a study on the effectiveness of neutralizing tactical defenses in psychotherapy and scanning psychotherapy Short-term defenses, anxiety and fear of intimacy have shown that eliminating tactical or external defenses rooted in the fear of re-emerging in intimacy and closeness can reduce interpersonal and interpersonal stress. In addition, this method of intervention can change some types of defense styles.

Ardabili, Borjali and Pezeshk (2018) in a study entitled the effectiveness of intensive and short-term psychotherapy on improving the mother-child conflict relationship, showed that intensive and short-term psychotherapy intervention has a positive effect on improving the quality of mother-child conflict and this effect was significant in three scales of the questionnaire.

\section{Research Method}

This research was a quasi-experimental design with pre-test and post-test with a control group in which two experimental groups and one control group were used. In this plan, the members of the groups were randomly selected and first a pre-test was taken from each group, an experimental intervention was applied to the groups and finally a post-test was performed from each group. The statistical population of the study included all mothers with mentally retarded children in Ahvaz in 2009-2010, which was performed on 45 of these mothers whose children were in one of the centers for mentally retarded children in Ahvaz. Samples were selected by convenience sampling method and selected by lot in three groups of 15 people including brain exercise test group, short-term psychodynamic test group and control group. 
In this research, each of the three groups of 15 mothers with mentally retarded children were affected by the experimental method, the first group during 12 sessions of 60 minutes under the brain exercise training program and the second group during 12 sessions of 60 minutes under mental Short-term scan therapy (ISDTP) but the control group did not receive training at this time.

Before the training programs, all mothers underwent pre-test and after 12 sessions, post-test was performed on all three groups. Criteria for inclusion in the study were having at least one mentally retarded child, consent to attend meetings, and not having a lateral psychological disorder and not using a specific psychological medication. Criteria for exit from the test were absence from two or more sessions of treatment and dissatisfaction with continued attendance.

\section{Research tools}

The instrument used in the research was Grant's Emotional Self-Awareness Questionnaire, which has 33 questions developed by Grant, Franklin and Longford (2002). This questionnaire is in the five-point Likert scale (from never 1 to very high 5). This questionnaire has 5 subscales which are recognition (with 6 questions), identification (5 questions), transformation (7 questions), environmentalism (10 questions) and problem solving (5 questions). The reliability of the questionnaire from Cronbach's alpha method in the research of Grant et al. (2002) was equal to 0.79 . The validity of the questionnaire was confirmed through consultation with professors. In Mahna and Talepasand (2016) research, the reliability of this questionnaire was 0.89 . In Farhadinia and Kafinia (2020) Cronbach's research was 0.74. In the present study, the reliability of the Emotional Self-Awareness Questionnaire was calculated to be 0.95 by Cronbach's alpha method.

\section{In the present study, two implementation methods have been used, which are as follows;}

A. Brain exercise: According to the treatment protocol of Denison and Denison (1994), after receiving a letter of introduction from the university and presenting it to the center for children with mental disabilities and attracting the cooperation of respected mothers, we attended the center for one day a week. At first, we talked to mothers with children with mental disabilities and after stating the situation, they were asked to participate in this study if they wished to cooperate. In the first face-to-face meeting with them, after a brief history of their current physical and mental condition and we discussion with them about the method of brain exercise and the process of working.

Before starting the movements, to prepare there are 4 pre-exercises that include drinking water, brain buttons, cross movements and connecting the muscles. This method consists of 26 simple movements performed in 12 sessions of 60 minutes (twice a week). These movements include eight-lazy movements, abdominal breathing, energy, owl movements, arm activity, leg stretching, leg pumping, ground connection, drinking water, balance buttons, space buttons, thinking helmet, balance, buttons terrestrial. These exercises were taught to mothers in four sessions (once a week).

B- Short-term dynamic psychotherapy: Short-term dynamic psychotherapy, ie the seven stages of asking questions about problems, pressure, challenge, transfer resistance, direct access to the unconscious, transfer analysis, and scanning the unconscious according to the Parie and Balland therapy protocol ( 2000; quoted by Mohammadzadeh and Hosseini, 2018 and quoted by Fooladi, Borujeni, Ranjbar Sudjani, 2018), as described in Table 1. 
Table 1.

Content of short-term psychodynamic psychotherapy sessions

\begin{tabular}{|c|c|}
\hline $\begin{array}{c}\text { Sessions } \\
1\end{array}$ & $\begin{array}{l}\text { Explain the rules of conducting treatment sessions and initial interview with the } \\
\text { implementation of a scan sequence, called experimental therapy, for the initial } \\
\text { evaluation of the problem. }\end{array}$ \\
\hline $\begin{array}{l}\text { Sessions } \\
2\end{array}$ & $\begin{array}{l}\text { In the second session, follow-up is done if the appropriate response to the } \\
\text { experimental treatment is given. From this meeting onwards, according to the type } \\
\text { of defense (eleven), appropriate and effective interventions related to each were } \\
\text { implemented. The types of common tactical defenses and effective interventions } \\
\text { for each were summarized as follows; }\end{array}$ \\
\hline 1 & $\begin{array}{l}\text { Working with tactical defenses of closed words (speaking in the envelope), all- } \\
\text { encompassing words and effective intervention: doubting, challenging, challenging } \\
\text { with defense. }\end{array}$ \\
\hline 2 & $\begin{array}{l}\text { Examining the specialized words used by mothers, tactical defenses of indirect } \\
\text { speech, and morbid and probabilistic thoughts. Effective Intervention: Challenge } \\
\text { with couples' defenses and identify speech, challenge with defense and hesitation } \\
\text { in defense. }\end{array}$ \\
\hline 3 & $\begin{array}{l}\text { Investigation of mental rumination defense and reasoning. Effective interventions, } \\
\text { respectively: clarification, requesting a definitive answer, challenge with defense, } \\
\text { challenge and doubt in defense. }\end{array}$ \\
\hline 4 & $\begin{array}{l}\text { Defenses of rationalization and generalization. Effective interventions: clarify, } \\
\text { block, challenge and identify, challenge with defense. }\end{array}$ \\
\hline 5 & $\begin{array}{l}\text { Deviation and forgetting tactics. Effective interventions: blocking defense and } \\
\text { hesitation in defense, challenge with defense. }\end{array}$ \\
\hline 6 & Denial, effective interventions: hesitation in defense, challenge with defense. \\
\hline 7 & $\begin{array}{l}\text { Externalization and ambiguity, effective interventions: clarification, challenge with } \\
\text { defense. }\end{array}$ \\
\hline 8 & $\begin{array}{l}\text { Avoidance, obsessive hesitation. Effective interventions: clarification, challenge } \\
\text { with defense. }\end{array}$ \\
\hline 9 & $\begin{array}{l}\text { Bodybuilding and acting as a defense against emotions. Effective intervention: } \\
\text { enlightenment. }\end{array}$ \\
\hline 10 & $\begin{array}{l}\text { Rebellion, disobedience. Chinese introduction, defensive cry and the range of } \\
\text { retreating defenses. Effective interventions: confrontation, challenge and direct } \\
\text { involvement, enlightenment. }\end{array}$ \\
\hline 11 & $\begin{array}{l}\text { Talking instead of touching emotions. Non-verbal signs. Follow - passivity. } \\
\text { Effective interventions: clarification. Doubt in defense, challenge with defense. } \\
\text { Turn on, challenge. }\end{array}$ \\
\hline
\end{tabular}

\section{Methods of data analysis}

The following statistical methods were used to analyze the data of this study of 3 variables in the multivariate variance grou: 
Using descriptive statistics indicators of frequency, frequency percentage, mean and standard deviation to describe the variables and demographic characteristics of the research subjects; Kolmogorov-Smirnov test (in order to observe the default of normal distribution of grades in the community); Levine test.

\section{Multivariate analysis of covariance}

Univariate analysis of covariance (in Mankova text)

Befroni post hoc test

SPSS23 and AMOS23 softwares was used for data analysis in this study.

\section{Research Findings}

\section{Descriptive findings}

Descriptive findings of this study include statistical indicators such as mean and standard deviation for all variables studied in the study. Table 2 shows the mean and standard deviation of emotional self-awareness in the groups of brain exercise training (1), short-term dynamic psychotherapy group (2) and control group (3) in the pre-test and post-test stages.

Table 2.

Mean and standard deviation of emotional self-awareness in brain exercise training groups (1), short-term dynamic psychotherapy group (2) and control group (3) in pre-test and post-test stages

\begin{tabular}{|c|c|c|c|c|c|c|c|}
\hline variable & groups & \multicolumn{2}{|c|}{ Group 1 } & \multicolumn{2}{c|}{ Group 2 } & \multicolumn{2}{c|}{ Group 3 } \\
\cline { 3 - 8 } & Mean & $\begin{array}{c}\text { standard } \\
\text { deviation }\end{array}$ & Mean & $\begin{array}{c}\text { standard } \\
\text { deviation }\end{array}$ & Mean & $\begin{array}{c}\text { standard } \\
\text { deviation }\end{array}$ \\
\hline $\begin{array}{c}\text { emotional } \\
\text { self- } \\
\text { awareness }\end{array}$ & pre-test & 87.87 & 10.84 & 85.73 & 10.47 & 87.47 & 12.24 \\
\cline { 2 - 8 } & pre-test & 96 & 11.86 & 92.8 & 10.69 & 88 & 12.04 \\
\hline
\end{tabular}

As can be seen in Table 2, in group 1 (brain exercise training), the mean and standard deviation of emotional self-awareness in the pre-test stage were 87.87 and 10.84, in the post-test stage were 0.96 and 86. 11. In group 2 (short-term scanning psychotherapy), the mean and standard deviation of emotional self-awareness in the pre-test stage were 85.73 and 10.47, in the post-test stage were 92.8 and 10.69. Also, in group 3 (control), the mean and standard deviation of emotional self-awareness in the pre-test stage were 87.47 and 12.24 and in the post-test stage were equal to 0.88 and 12.04 , respectively.

\section{Findings related to research hypotheses}

To test the research hypotheses were used multivariate analysis of covariance, univariate analysis of covariance (in Mankova text) and Bephroni post hoc test. To compare experimental and control 
groups based on post-test scores, after controlling for the effect of pre-tests, to determine the effect of short-term dynamic brain exercise training and psychotherapy on emotional self-awareness, first a multivariate analysis of covariance (Mankova) on the data was performed, then the research hypotheses were tested. The results of multivariate analysis of covariance are shown in Table 3.

Table 3.

Results of multivariate analysis of covariance (MANCOVA) on post-test scores of emotional selfawareness in experimental $(1,2)$ and control groups

\begin{tabular}{|l|l|l|l|l|l|}
\hline analysis & scores & F & Df & df & $\begin{array}{l}\text { The } \\
\text { significance } \\
\text { level }\end{array}$ \\
\hline Pilay effect & 1.08 & 14.96 & 6 & 76 & 0.001 \\
\hline Wilks Lambda & 0.07 & 32.24 & 6 & 74 & 0.001 \\
\hline Hoteling effect & 9.97 & 59.86 & 6 & 72 & 0.001 \\
\hline The biggest root on & 9.76 & 123.66 & 3 & 38 & 0.001 \\
\hline
\end{tabular}

As can be seen in Table 4, the multivariate analysis of covariance (MANOVA) statistical tests in the groups of brain exercise training, short-term dynamic psychotherapy and control show that these groups have a significant difference in at least one of the interrelated variables. Therefore, Hypothesis 1 of the research is confirmed.

\section{Table 4.}

Results of univariate analysis of covariance in Mankova text on emotional self-awareness posttest scores

\begin{tabular}{|l|l|l|l|l|l|l|}
\hline Variable & $\begin{array}{l}\text { Total } \\
\text { squares } \\
\text { of } \\
\text { freedom }\end{array}$ & $\begin{array}{l}\text { Degrees } \\
\text { squares }\end{array}$ & F & $\begin{array}{l}\text { The } \\
\text { significance } \\
\text { level }\end{array}$ & Effect size \\
\hline $\begin{array}{l}\text { emotional } \\
\text { self- } \\
\text { awareness }\end{array}$ & 10.78 & 2 & 255.39 & 36.69 & 0.004 & 0.65 \\
\hline
\end{tabular}

As can be seen in Table 4, the $\mathrm{F}$ ratio of univariate analysis of covariance for emotional self-awareness $(\mathrm{F}=36.69$ and $\mathrm{P}<0.05)$ was obtained. This finding shows that there is a significant difference in the dependent variable of emotional self-awareness between the groups of brain 
exercise training and short-term dynamic psychotherapy and control. Therefore, Hypothesis 1 of the research is also confirmed in terms of univariate covariance.

To answer Hypotheses 2 and 3 and to exactly determine which of the three groups differs in the dependent variables, the Benferoni post hoc test was used, the results of which are presented in Tables 7 and 8 . Table 5 shows the adjusted mean, standard error, low limit and high limit of the research variables in the three groups of experiment 1, experiment 2 and control.

Table 5.

Adjusted mean, standard error, low limit and high limit of research variable in three experimental groups

\begin{tabular}{|c|c|c|c|c|c|}
\hline \multirow[b]{2}{*}{ variable } & \multirow{2}{*}{ group } & \multicolumn{4}{|c|}{ Statistical indicators } \\
\hline & & mean & standard error & low limit & high limit \\
\hline \multirow{3}{*}{ emotional } & $\begin{array}{l}\text { brain exercise } \\
\text { training }\end{array}$ & 95.12 & 0.68 & 93.74 & 96.51 \\
\hline & $\begin{array}{c}\text { short-term } \\
\text { dynamic } \\
\text { psychotherapy }\end{array}$ & 94.15 & 0.68 & 92.76 & 95.54 \\
\hline & control & 87.51 & 0.68 & 86.13 & 88.9 \\
\hline
\end{tabular}

As can be seen in Table 5, the adjusted mean of brain exercise training and short-term dynamic psychotherapy is favorable and significant with the control group.

Table 6 presents the results of the Benferoni post hoc test to compare the adjusted means of the emotional self-awareness variable in three groups of brain exercise training (1), short-term dynamic psychotherapy group (2) and control group (3).

\section{Table 6.}

Results of Benferoni post hoc test to compare the adjusted means of emotional self-awareness of experimental and control groups in the post-test stage

\begin{tabular}{|l|l|l|l|l|l|}
\hline variable & $\begin{array}{l}\text { Compared } \\
\text { groups }\end{array}$ & $\begin{array}{l}\text { adjusted } \\
\text { means }\end{array}$ & $\begin{array}{l}\text { means } \\
\text { difference }\end{array}$ & $\begin{array}{l}\text { The standard } \\
\text { error }\end{array}$ & $\begin{array}{l}\text { The } \\
\text { significance } \\
\text { level }\end{array}$ \\
\hline \multirow{2}{*}{$\begin{array}{l}\text { emotional } \\
\text { self- } \\
\text { awareness }\end{array}$} & 1 and Control & $95.12,87.51$ & 7.61 & 0.96 & 0.001 \\
\cline { 2 - 6 } & 2 and Control & $94.15,87.51$ & 6.63 & 0.97 & 0.001 \\
\cline { 2 - 6 } & 1 and 2 & $95.12,94.15$ & 0.97 & 0.97 & 0.97 \\
\hline
\end{tabular}


As can be seen in Table 6, the difference between the mean of the control group and brain exercise training in emotional self-awareness is 7.61 , which is significant at the 0.05 level.

This finding shows that there is a significant difference between the control group and brain exercise training in emotional self-awareness in favor of brain exercise training. This finding confirms the research hypothesis 2 . Also, the difference between the mean of the control group and short-term dynamic psychotherapy in emotional self-awareness is 6.63 , which is significant at the level of 0.05 .

This finding shows that there is a significant difference between the mean of the control group and the mean of brain exercise training in emotional self-awareness in favor of short-term dynamic psychotherapy. However, the difference between the mean of the brain exercise training group and the short-term dynamic psychotherapy group in emotional self-awareness is equal to 0.97, which is not significant at the level of 0.05. This finding refutes Hypothesis 4 .

\section{Discussion}

Explaining the results of this study, it can be inferred that mothers suffer from very vulnerable conditions due to the birth of mentally retarded children and even suffer a lot of stress. Stress disrupts a person's functioning in the social, psychological, physical and family. Occupational dissatisfaction reduced production, increased errors and accidents, lower judgment and slow reaction time. Social and family relationships disrupted by creating psychological changes such as increased irritability, anxiety, stress, nervousness and inability to control oneself, weakens in the role of parent or weakens the immune system that makes the body susceptible to diseases and reduces his efficiency before and after the onset of the disease (Mohammadi, 2015). Based on this, psychological therapies can probably help the process of improving the condition of mothers and reducing their psychological damage. These include short-term scanning brain exercise and psychotherapy. Exercise therapy helps mothers with mentally retarded children to have a better life. Brain exercise is a set of sports movements that stimulate the brain, promote nerve conduction and facilitate learning in the brain. This program is based on the belief that learning problems are caused by a mismatch between the brain and the body and thus reduce a person's ability to learn (Abduh and Tahar, 2018). Intensive and short-term dynamic psychotherapy techniques are also based on the type of therapeutic relationship and enhance the parent-child relationship through a sense of proper attachment between parent and child. Dovanloo (1987) also believes that the only capacity for warm bonds with parents is innate and can be achieved through dynamic psychotherapy and brain exercise techniques by influencing the condition of traumatized mothers to have mentally retarded children by increasing emotional self-awareness and control it, manage the stress due to the birth of a mentally retarded child and take care of him and feel the adequacy and mastery of the conditions of mothers of mentally retarded children.

As can be seen in Table 4, the $\mathrm{F}$ ratio of univariate analysis of covariance for emotional self-awareness $(\mathrm{F}=36.69$ and $\mathrm{P}<0.05)$ was obtained. These findings show that there is a significant difference in the dependent variable including emotional self-awareness between the groups of brain exercise training and short-term dynamic psychotherapy and control. Therefore, Hypothesis 4 of the research is confirmed.

As can be seen in Table 6, the difference between the mean of the control group and brain exercise training in emotional self-awareness is 7.61 , which is significant at the 0.05 level. This finding shows that there is a significant difference between the control group and brain exercise training 
in emotional self-awareness in favor of brain exercise training. This finding confirms the research hypothesis 2 . Also, the difference between the mean of the control group and short-term dynamic psychotherapy in emotional self-awareness is 6.63 , which is significant at the level of 0.05 .

This finding shows that there is a significant difference between the mean of the control group and the mean of brain exercise training in emotional self-awareness in favor of short-term dynamic psychotherapy. However, the difference between the mean of the brain exercise training group and the short-term dynamic psychotherapy group in emotional self-awareness is equal to 0.97 , which is not significant at the level of 0.05 .

This finding shows that there is no significant difference in emotional self-awareness between the mean of the brain exercise training group and the short-term dynamic psychotherapy group. This finding refutes the research hypothesis 4 .

It can also be inferred that mothers of mentally retarded children have physical disorders and even psychosomatic disorders based on confusion and sometimes anger and guilt due to the birth of this child and therefore less aware of the process of their emotions. This point leads to the use of inappropriate emotions in certain situations and sometimes causes a lot of damage to family and social relationships of this group of mothers. In such situations, their level of emotional selfawareness decreases and due to the difficult situation they are in, they sometimes lose the ability to manage their lives. Accordingly, the use of psychotherapy and various methods to increase mental strength such as brain exercise and short-term dynamic psychotherapy can improve the condition of mothers. The tasks created by brain exercise is the coordination of both hemispheres of the brain (Kim and Cho, 2016). It also stimulates the atrial system by activating both hemispheres of the brain through motor and sensory cortices, and increases the performance of children with intellectual disabilities in the learning process by reducing the mechanism of war and escape. People can receive and express information simultaneously after performing these brain exercise movements (Kim and Cho, 2016). On the other hand, in short-term dynamic psychotherapy, the clarification of defenses and the pressure to experience emotions and challenge the patient's defenses, should start from the beginning of the treatment process.

The results of this study are consistent with the findings of Nabizadeh, Farhadi, Rashid and Kordonkhabi (2019), Pasdani Ardabili, Borjali and Pezeshk (2018), Dave et al. (2014), Gholizadeh et al. (2018), Rashid and Hosseini Asl Nazarloo (2016), Hajloo and Molaei (2019), Bayanfar and Mousavi Tabatabai (2019), Fooladi et al. (2018); Rezaei, Ghazanfari and Rezaian (2017); Mokhtarian, Yaryari and Mokhtarian (2015).

\section{Referencces}

Hagh Ranjbar, F. Kakavand, A. Borjali, A. and Barmas, H. (2011). Summer and quality of life of mothers with mentally retarded children. Journal of Health and Psychology. 1 (1) pp. 177187.

Rashid, K. and Hosseini Asl Nazarloo, M. (2017) Investigating the effect of sex education on increasing parents' sexual knowledge and their sense of adequacy. Theology of KnowledgeResearch, Education and Evaluation, 143-162.

Rezaei, F. Ghazanfari, F. and Rezaian, M. (2017). The effectiveness of positive parenting group education on parenting stress and self-efficacy of mothers and behavioral problems of students with mental retardation. Journal of Health Resonance, 7-12. 
Astrology, A. (2015). Comparison of metacognitive beliefs and coping strategies in mothers of mentally retarded and normal children. Master Thesis in General Psychology, Azad University, Shahroud Branch.

Foladi, F. Kaviani Borujeni, M. Varanjbarsudjani, Y. (2017). The effectiveness of short-term intensive dynamic psychotherapy for social anxiety of mothers with children with Asperger's Syndrome, Exceptional Children Quarterly, 55-64.

Qoli Zah, M. Khosropour, F. Pourranjbar, M. and Khodadadi, M. R. (2016). The effect of aerobic exercise, anaerobic and relaxation on reducing stress and anxiety of female medical students of Kerman University of Medical Sciences. Journal of Health and Development, 7 (4), pp. 333-334.

Mohammadzadeh, J. and Hosseini, Z.S. (2018). The effectiveness of intensive short-term psychotherapy (ISDTP) on promoting hope and happiness in people with cancer. Journal of Health Psychology. 77.151-131, (3).

Mohammadi, S. (2015). Investigating the relationship between organizational identity, job stress, job satisfaction and organizational commitment among high school teachers in Sanandaj. Master Thesis, University of Tehran.

Mokhtarian, T. Yaryari, F. and Mokhtarian, T. (2015). The effectiveness of brain exercise on reducing maternal stress, reducing hyperactivity and increasing attention in children with attention deficit / hyperactivity disorder and reducing their stress. Exceptional Children Quarterly, 32-40.

Abduh, B. and Tahar, M.M. (2018) The Effectiveness of Brain Gym and Brain training intervention on working memory performance of student with learning disability. Journal of ICSAR. V 2. Issue 2. P 105-111.

Ardian, I and Nurain, N. (2018) The Effectiveness of Brain Gym and Brain Vitalization Gym in Increasing Cognitive Function of the Elderly in PucangGading Social Rehabilitation Unit of Semarang. Nurseline Journal. V 3. Issue 1. P 38.

Bayanfar, Fatemeh, Mousa Tabatabae, Seyed. (2019). The Effectiveness of Brain Gym in Increasing Academic Self-Efficacy, Academic Performance and Reduction Concentration and Attention Defect of University Student. Organizational Behavior Management in Sport Studies, Vol. 6, No.21,Spring 2019 Pp: 45-54.

Chang, V.Y., Palesh, O., Caldwell, R., Glasgow, N., Abramason, M., Luskin, F., Gill, M., Burke, A., \& Koopman, C. (2004). The effects of a mindfulnessbassed stress redction program on stress, mindfulness self-efficacy positive states of mind. Journal of Stress and Health, 20, $141-147$

Dave, D., Mittal, S., Tiwari, D., Parmar, M. C., Gedan, S., \& Patel, V. (2014). Study of anxiety and depression in caregivers of intellectually disabled children. Journal of Research in Medical and Dental Science, 2(1), 8-13.

Davanloo, H. (1980). Short-term dynamic psychotherapy. New York: Jason Aronson.

Dennison, P. E, \& Dennison, G. E. (1994). Brain Gym ${ }^{\circledR}$ teacher's edition-Revised. Ventura, CA: Edu-Kinesthetics.

Dennison, P. E., \& Dennison, G. E.(1986), Simple Activities for Whole Brain Learning ;USA. 
Driessen, E., Cuijpers, P., Matt, S.C.D., Abbass, A.A., Jonghe, F.D., \& Dekker, J.J.M. (2009). The efficacy of short-term psychodynamic psychotherapy for depression: meta-analysis. Department of Clinical Psychology.

Fisher,M (1990).Parenting Stress and the child with attention deficit hyperactivity disorder. journal of clinical child psychology,19,337-346.

Hajloo N, Mowlaie M. (2019). Comparison the effectiveness of empathic and anxiety regulating dynamic psychotherapies on symptom reduction and defense mechanism of students with symptoms of adult separation anxiety disorder. CPAP. 17 (1) $11-10$ URL: http://cpap.shahed.ac.ir/article-1-1381-en.html

Hannaford ,C (2005), Smart Moves : why learning is not all in your head; United States of America.

Kim, N.H. and Cho, H.M. (2016). How the Brain-Gym influences the Emotional Anger. Institute for Education and Research Gyeongin National University of Education. V 36. Issue 3. P 65-111.

Nabizadeh A, Farhadi M, Rashid K, Kordnoghabi R. (2019). The Effectiveness of Tactical Defenses Neutralization in Intensive Short-Term Dynamic Psychotherapy on Defensive Styles, Anxiety, and Fear of Intimacy in Non-Clinical Sample. Journal of Research in Psychological Health. 13 (1):24-39. [Persian].

Orsillo, S.M., \& Roemer, L.B. (2005). Acceptance and Mindfulness-Based Approaches to Anxiety Conceptualization and Treatment. United States of America, Springer, 131- 147.

Pasbani ardabili, M., Borjali, A., \& Pezeshk, Sh. (2018). The Effectiveness of Intensive ShortTerm Dynamic Psychotherapy to Improve the Conflictive the Relationship between MotherChild. Quarterly of Clinical Psychology Studies, 8(30), 139-162.

Perry, J. C., \& Bond, M. (2000). Empirical studies of psychotherapy for personality disorders. In psychotherapy for personality disorders. Edited by Gunderson J. G., Gabbard G.O. Washington, DC: American Psychiatric Press. 